\title{
Moderate Intensity Exercise Is Associated with Decreased Angiotensin-Converting Enzyme, Increased ß2-Adrenergic Receptor Gene Expression and Lower Blood Pressure in Middle-Aged Men
}

\author{
TEIXEIRA AM ${ }^{1},{\text { TARTIBIAN } \mathrm{B}^{2} \text {, and BAGHAIEE B }}^{2}$
}

1. Research Center for Sport and Physical Activity, Faculty of Sport Sciences and Physical Education, University of Coimbra, Coimbra, Portugal.

2. Faculty of Physical Education and Sport Science, Urmia University, Urmia, Iran.

\footnotetext{
ABSTRACT

Introduction: Exercise activity increases blood flow rate but gene expression of factors that may be involved in blood pressure changes have not yet been completely studied. The purpose of the present study was to characterize the role of aerobic exercise with the intensity of 50-65\% maximal exercise heart rate in gene expression of angiotensin converting Enzyme (ACE) and $\beta 2$-adrenergic receptor (ADRB2) in adult untrained men.

Methods: Twenty untrained middle aged men (49.91 \pm 3.17 years) volunteered to participate in this study. The participants were randomly assigned to exercise $(E x, n=10)$ and control (Con, $n=10)$ groups. The Ex group performed aerobic exercises for 40-50 min/day, 4 days/week for 8 weeks. Expression of ACE mRNA and ADRB2 mRNA were determined by real time PCR at the start of the exercise program, 24 hours after the last training session at the end of week 4 and at the end of week 8 . Blood samples were collected following a 12-hour overnight fast and were taken between 08.00-09.00h. Descriptive statistics were determined for all variables. The normal distribution of data was determined by Kolmogorov-Smirnov test. Data were analyzed using appropriate Mixed Model Method (One-way ANOVA). Post hoc comparisons between selected means were performed with Bonferroni's contrast test when initial ANOVA indicated statistical differences between experimental groups. MannWhitney analyses were used to compare differences between groups (control and exercise groups) at baseline.

Results: The expression of ACE mRNA in week 4 and in the Ex group was significantly lower than in the Con group $(\mathrm{P}<0.001)$. In the Con group the expression of ACE mRNA significantly increased in week $8(\mathrm{P}<0.001)$. ADRB2 mRNA in Ex group in week 4 and in week 8 was markedly higher than in the Con group $(\mathrm{P}<0.001)$. In the Con group the expression of ADRB2 mRNA decreased.

Conclusions: These results suggest that moderate intensity exercise promotes the leukocyte expression of gene markers that may affect blood pressure and decreases blood pressure by improving cardiovascular fitness levels in middle-aged men
} 